\title{
Role of Shared Information Systems in Distribution Channels ${ }^{1}$
}

\author{
José M. Sánchez. Universidad Pablo de Olavide. Spain \\ jmsanvaz@upo.es
}

Carolina Ramírez. Universidad Pablo de Olavide. Spain cramgar@upo.es

\begin{abstract}
Some manufacturers are reluctant to rationally share their Information Systems (ISs) with their dealers. Through a detailed case study analysis, we explore what could impel a manufacturer to overcome its reluctance by analysing its control problems (lack of direction; motivational; and personal limitations). We show that sharing ISs provides benefits derived from the collection of information in both quantity and quality that is in turn utilized by the manufacturer. It ensures that the manufacturer controls operations with proper information, seeing the market through dealers. Therefore, manufacturers could share ISs in order to proactively manage their distribution channels in a non-coercive way.
\end{abstract}

Key words: Information Systems, Control Problems, Distribution Channel, Case Study.

\section{INTRODUCTION}

Facing the challenges associated with getting a product to the right place at the right time at the lowest cost, a manufacturing firm may sell their products through a set of independent firms (Stern et al., 1996). These dealers have greater market knowledge and flexibility, giving the manufacturer cost and investment reductions (Celly and Frazier, 1996). However, once the distribution channel

1 This research is partly funded by the research project SEJ-111 and SEJ2005-06652/ECON. 
is established, differences in objectives arise (Stern et al., 1996) and there is a lack of the advantages of a hierarchical structure (Gulati and Singh, 1998). This may be aggravated by the influence that a bad dealer's service could have on the manufacturer's reputation.

In this sense, shared information, in terms of the extent to which channel members proactively exchange information with each other, has been found to be critical for the effective functioning of distribution channels (Li and Dant, 1997). Thus, Information Systems (ISs) could enhance these inter-firm relationships (Ritter and Gemünden, 2003), facilitating an efficient and effective informational flow. Integration and coordination via IS has become a key to improved distribution channel performance (Barut et al., 2002). However, although scholars and practitioners in various fields have turned their attention to sharing information, it appears that manufacturers harbor a disinclination to reveal more than minimal information since such disclosure could be perceived as a loss of control. Owing to the adversarial nature of business, managers tend to overestimate the possible risks without seeing the potential benefits and thus are reluctant to share information with their partners (Huang and Gangopadhyay, 2004). Previous research suggests that shared ISs could create perceived risks from privacy concerns, in turn making the system vulnerable to fraud (Papazoglous, 2000; McKnight et al., 2002).

Recognizing this gap, and according to Baiman and Rajan's (2002) proposal, our aim is to explore what impels a manufacturer to rationally share its ISs in its established distribution channel. In this vein, to understand the need for shared ISs, we distinguish three control problems: lack of direction, motivational problems, and personal limitations, extending Merchant and Van der Stede's (2003) framework to distribution channels. This allows us to analyse whether Merchant and Van der Stede's control problems, defined for intra-organizational settings, persist in outsourced distribution channels. An exploratory case study approach (Yin, 1984) has been adopted because it allows us to capture the complexities of distribution channels. As a research site, we studied the distribution channel of a manufacturing firm called CMD (an assumed name). This is because, during the period of study 1985-2004, the firm has opted to share its ISs with its dealers.

Our research contributes to the existing literature in different ways. We focus on the manufacturer's perspective in a market-focused relationship as a potential ISs developer and information sharer to analyse what motivated it to develop shared 
ISs. Through the analysis of control problems, we defend that they persist in an inter-organizational context. Thus, the need to manage these control problems motivate that manufacturers develop shared ISs, in contrast to previous research that defended the proposition that outsourced distribution channels avoided the need for administrative systems. In addition to the assumption of existing literature on sharing information that improves inter-firm coordination, sharing ISs can also help the manufacturing firms to acquire increasingly reliable information to better control its distribution channel members' activities. We find that sharing IS provides benefits derived from the timely collection of information in both quantity and quality that the manufacturers can then utilize. Therefore, manufacturers, overcoming their reluctance, could share their ISs in order to proactively manage their distribution channel in a non-coercive way, controlling the end-market through their dealers.

The paper is structured as follows. First, we analyse the distribution channel context and its potential control problems, studying the role of shared ISs. Secondly, we present a case study of how CMD introduced a set of shared ISs tools to support its distribution channel management efforts. This case description is followed by a discussion and explanation of case findings, followed by conclusions.

\section{THEORETICAL BACKGROUND}

As parts of supply chains, distribution channels are configured as non-equity contractual alliances, with closer interactions than arms-lengths relationships. Within distribution channels typologies, we focus on industrial dealers, who have three distinctive features: 1. a revenue-sharing contract offered by the manufacturer; 2. a production or inventory quantity and retail price decision made by the manufacturer; and 3. inventory consignment, i.e., full ownership of inventory retained by the manufacturer. Under the consignment contract, a bigger upstream manufacturer delegates to smaller downstream dealers the exclusive rights to a customer's segment. Dealers give the manufacturer cost and investment reductions, in addition to greater flexibility and continuity (Stern et al., 1996). Furthermore, dealers can generate synergies when they represent various manufacturers (noncompetitors), and when they perform tasks that a single product cannot justify. In this line, the literature on marketing supports the view that fully-owned distribution channels require investment in administrative systems to 
manage activities, and that manufacturers could choose to avoid these by opting for a distribution channel (Anderson and Oliver, 1987).

Despite the benefits of distribution channels, the consensus of many researchers is that conflict is pervasive throughout all distribution channels (Stern et al., 1996). Distribution channels are composed of independent dealers with individual preferences, which could imply that the manufacturer depends on (and delegates authority to) a set of dealers to deliver goods and services to the selling point. In this sense, dealers could focus their behaviours on short-term profits, abandoning activities with no immediate and concrete pay-off, which could harm manufacturer objectives (Anderson, 1985). The problems could be aggravated when the manufacturer feels that dealers are irreplaceable because they have closer relationships with end customers or have better local market knowledge. In this sense, we propose to extend to an inter-organizational context the framework proposed by Merchant (1985) and Merchant and Van der Stede (2003). These authors argue that in an intra-organizational context, the need for control systems is rooted in control problems. Establishing that control problems can occur simultaneously, Merchant and Van der Stede (2003) classify them into three broad categories: (i) Lack of direction: when people do not know what the organization wants from them; (ii) Motivational problems: when people and organizational objectives do not naturally coincide, and people are self-interested; and (iii) Personal limitations: when people are simply unable to do a good job because of certain personal limitations, highlighting that a common limitation is a lack of information.

Some authors argue that the effective management of distribution channels requires manufacturers to increase information availability for internal users as well as authorized dealers. Integration and coordination via ISs has been found to be key to improved distribution channel performance (Barut et al., 2002). Thus, ISs could represent a valuable information resource management philosophy rather than just a technical systems issue (Arunachalam, 2004). ISs could allow efficient and effective flows of both informational and physical goods in a seamless fashion. Sharing information enables firms to coordinate and pursue common objectives (Arunachalam, 2004). Its inherent flexibility could help firms to quickly adopt new measures to adapt to changes in the environment (Chandrashekar and Schary, 1999). Porter and Millar (1985) related ISs to the value chain, concluding that the 
main purpose of ISs was to coordinate activities in the chain. In this sense, ISs ensures consistent information for all centres, avoiding information duplication and enhancing decision-making processes.

However, although ISs have been adopted in a diversity of organizations and the degree of penetration is exceptionally high, they are not so common in distribution channels. Although scholars and practitioners in various fields have turned their attention to sharing information, it appears that managers of manufacturing firms have a disinclination to give away more than minimal information since disclosure is perceived as a loss of control. Owing to the adversarial nature of business, managers are reluctant to share information with their partners because they tend to overestimate the possible risks without seeing the potential benefits (Huang and Gangopadhyay, 2004). In fact, some authors argue that a shared IS increases perceived risks from privacy concerns, in turn making the system vulnerable to fraud (Papazoglous, 2000; McKnight et al., 2002).

Nevertheless, studies concerned with the role of data interchange among various partners have not received the attention they deserve (Lau and Lee, 2000). The large investment in a shared IS and its inherent risks may be concerns for reasonable managers, raising some questions that need further research. The loss of resources -money and manpower - when implementations are flawed or fail is huge (Robey et al., 2002). Thus, according to the above arguments, our research question arises: What could impel manufacturing firms to share their proprietary ISs?.

\section{DESIGN AND CASE STUDY RESEARCH}

In order to provide an answer to our research question, following a design by Yin (1984), we conducted a case study from the perspective of a manufacturing firm called CMD (an assumed name). As a part of a larger research project, our field study was chosen based on two considerations: (1) the distribution channel was successful, longstanding, and stable; (2) the case showed that CMD, during the period of study 1992-2004, opted to share its ISs with its dealers. In line with Yin's (1984) suggestions, we followed three principles to provide validity and reliability: using multiple sources of evidence; creating a case study database; and maintaining a chain of evidence. 


\subsection{Data collection and analysis}

The necessary information to establish the sequence of analysed events was obtained by means of archival sources, direct observations, and interview data. The most rich and detailed archival sources were the different types of contracts, the dealers' evaluation system, the summary of all the periodical joint meetings, and the projects and procedures documents. Supplementary archival data contain a large number of financial and commercial reports, improvement project reports, and internal and external newsletters. Interviews were employed to gain more information and to complement and contrast the archival data, which served to triangulate our findings (Eisenhardt, 1989). On the basis of the revised literature, a guide for semi-structured interviews was developed to focus on the process of data collection in the development of the ISs. Thus, the interviews with the employees of CMD were carried out with a double aim: (a) to complete and to contrast the previously gathered information; and (b) to deepen understanding of aspects that were ignored and that were especially interesting in the study. We interviewed 20 members of CMD's management team face-to-face (November 2002 to June 2003). Interviewees were chosen based on their direct relation to the dealers' IS development. All interviews were tape-recorded and transcribed, and the completed write-up was sent to the interviewees for comment. We also assisted in the four joint meetings (2001-2004), as well as several informal meetings and phone conversations with some of CMD's managers and dealers.

In our research, we analysed the case data, focusing our efforts on the events that appeared to have an impact on the shared IS development process, a technique that can provide insight into "what led to what, and when" (Miles and Huberman, 1994, p. 110). This procedure helped us to trace four events that were chronologically ordered, in order to maintain the chain of evidence.

\subsection{Distribution channel information system at CMD}

CMD was established in the late 19th century and it is currently the leader in its Spanish chemical sector. Its outsourced distribution channel is configured as a non-equity alliance with a set of dealers, who sell its products to a great number of small and medium sized businesses. Dealers receive its products under consignment, and are delegated the activities of commercialisation, warehousing, 
transport, and management of CMD customers' portfolios. Although its industrial products are commodities that do not differ from those of its competitors, CMD's approach to working with its dealers is its main value. According to interviews, its distribution channel management allows it to differentiate itself from competitor firms, provide its final customers with a satisfactory service level, and maintain market premium prices.

\subsubsection{Distribution channel information system development}

Antecedents. From its beginning, CMD entrusted in some transporters with its delivery and warehousing tasks for two primary reasons: logistic costs and market positioning. From 1985 onwards, CMD began to establish the contractual framework of the relationship, focusing on the legal and labour aspects. As a result, a sole contract type is used for these independent entities, regardless of their varying sizes, legal constitution, and other activities. Also, CMD took advantage of the introduction of the contract to establish the sales commission system. Thus, the dealers operate in exclusivity and they are commissioned by its sales in a geographical area. However, on occasions, it is CMD who carries out the deliveries to the customer. On the other hand, CMD established its commercial department in the late 1980s to carry out the commercial functions of direct sales and attending to customers. CMD assigned each commercial employee a dealers group to supervise all its activities.

Although the sales were carried out through the distribution channel, CMD billed its customers directly. This is because CMD sent books of delivery notes, which the dealers completed manually for each product delivery. These notes were sent once a month by postcard to the different centres of CMD for their records. With this system, CMD carried out the billing for its products to the final customers, but it could neither foresee nor assign appropriate stocks to the dealers, overstocking its own and dealers' warehouses. At the same time, many errors of billing were detected.

In order to preserve the chain of evidence, the facts are structured in order to show the chronological evolution of IS development in the period of study, 19922004. Figure 1 summarizes the time line associated with these events. 


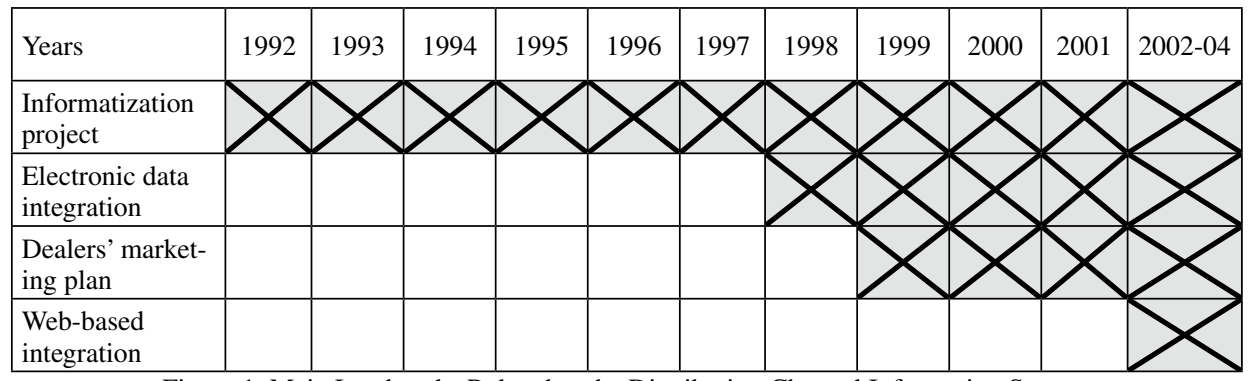

Figure 1. Main Landmarks Related to the Distribution Channel Information System

\section{Informatization project}

In 1992, CMD hired a consultant firm to analyse its entire business. The consultants recommended transferring the distribution channel to re-sellers (like its competitors). CMD's managers considered that this option could facilitate the administrative tasks and the dealers' control, but that in turn they would lose the control of the containers and of the final market, aspects that lead it to refuse the proposal.

Instead, CMD decided to install computers and software in large dealerships (more than 120 invoices of products/month delivery). The software specifically developed for these dealers allowed them to outsource the administrative activities of product delivery and the release of invoices, which, from that moment on, were only the responsibility of the dealers. Also, with the information transmitted twice monthly via modem, CMD was able to know the location of containers and to obtain twice-weekly information on sales, stocks of dealers, and final customers. Also, with the new systems, the dealers recorded all their invoices, which resulted in the reduction of errors and reduced paperwork. This allowed CMD to carry out gradual staff reductions, closing some own centres and reducing the workload of others.

\section{Electronic data integration}

As a continuation of the above project, CMD installed new computers and its own software, sharing it with all its dealers and delegating new functions to them (opening and maintenance of customers' records, discounts in prices, invoice copies, dealers' and customers' stock control, logistic management, complaints recording, and customers' debt control). Thus, they also increased the externalisation of 
activities, and maintained the control through the establishment of authorization procedures and passwords. This system, with twice weekly reporting, allowed CMD to increase their knowledge of the allocation of inventory between dealers, gaining greater information and control of dealers. According to the interviews and the documents, with these new systems they not only eliminated a significant quantity of work, reduced stocks, and increased the rotation ratios in warehouses, but they also avoided errors and increased the information from (and the control of) the dealers.

\section{Dealers' marketing plan}

The dealers' marketing plan was based on two key planks: (a) a "dealers' scorecard"; and (b) a data base:

-(a) Dealers' scorecard. CMD established a computer application (“dealers control scorecard") to share commercial information with its dealers, which was given the same name as the internal tool for the commercial department: "gescom". The intention was: "to improve coordination between our commercial staff and dealers. The information would allow the dealer to: (i) obtain better knowledge of the evolution of its customers; (ii) plan and solve problems more quickly; (iii) coordinate its work with the sales network" (Project Memory). This information allowed dealers to have the necessary information to improve their sales activities, and it included falls in consumption, signing of new customers, package contracts, analysis of sales vs. previous year, analysis of sales by concepts, or the stock of packages by the customers. The commercial department provided training in the use of the new information, because although dealers already had access to it (through customer invoices copies) this more organised and aggregated format was more helpful. This information also allowed the establishment and pursuit of the dealers' objectives and improvement projects. This IS, in some cases, even improved the manufacturer's own commercial department activities by providing an extra management tool.

-(b) Dealers' database. This internal tool gathers information on the different tasks and functions of the dealers (e.g., sales, commissions, dedication percentage, number of sales staff, capacity of trucks, or customer attention schedule). The interviewees consider it a tool enabling them to carry out benchmarking analysis and to evaluate each dealer's evolution. 


\section{Web-based integration}

At the present time, the ISs is completely integrated through different databases with on-line access via the Internet. CMD has designed a web page that currently includes all of the former tools, as well as some new services. As the dealers' manager comments in an e-mail of July 2002: "The sections that compose the dealers' web are: - the Dealers' Handbook, information and operational norms of the functions carried out by the dealers. - Dealer's addresses, to locate and obtain the data from dealers, as well as the activities that develop. [...] - CMD News: communication magazine for dealers - Services that CMD offers to dealers, such as civil responsibility insurance, safety consultation, or ISO-9000. - Dealer News: to publish opinions, applications or offers. - Basic computer applications, and - email addresses for each dealer to facilitate communication with the customers and with CMD".

Since 1999, CMD observes a strong cost reduction and a sales increase (see Figure 2). The cost reduction is mainly based on the closure of own centres and on the reductions in CMD's staff. Likewise, the sales increase can be attributed to several factors, among which are the evolution of the market itself, the premium prices policy, the dealers' sales focus, the introduction of new services supplied by the dealers (services which are billed by CMD to the final customers), and to allow to CMD's commercial department to give more attention to another market functions. Finally, in the course of this shared ISs establishment, a reduction in the number of dealers has been observed, falling from almost 300 dealers in the late 1980's to 178 at present. CMD managers highlight the fact that it has been necessary to reduce the number of small dealers, assigning their area to other more medium sized dealers.

\begin{tabular}{|c|c|c|c|c|c|}
\hline Year & No. Dealers & & Direct Sales & Dealers Sales & Total \\
\hline \multirow{2}{*}{1997} & \multirow{2}{*}{220} & $\$ M M$ & 36 & 71 & 107 \\
\hline & & $\%$ & $34 \%$ & $66 \%$ & \\
\hline \multirow{2}{*}{1998} & \multirow{2}{*}{218} & $\$ M M$ & 38 & 78 & 116 \\
\hline & & $\%$ & $33 \%$ & $67 \%$ & \\
\hline \multirow{2}{*}{1999} & \multirow{2}{*}{214} & $\$ M M$ & 29 & 78 & 107 \\
\hline & & $\%$ & $27 \%$ & $73 \%$ & \\
\hline 2000 & 201 & -- & -- & -- & - \\
\hline \multirow{2}{*}{2001} & \multirow{2}{*}{195} & $\$ M M$ & 40 & 78 & 118 \\
\hline & & $\%$ & $34 \%$ & $66 \%$ & \\
\hline \multirow{2}{*}{2002} & \multirow{2}{*}{188} & $\$ M M$ & 47 & 84 & 131 \\
\hline & & $\%$ & $36 \%$ & $64 \%$ & \\
\hline \multirow{2}{*}{2003} & \multirow{2}{*}{181} & $\$ M M$ & 45 & 95 & 140 \\
\hline & & $\%$ & $32 \%$ & $68 \%$ & \\
\hline 2004 & 178 & -- & -- & -- & - \\
\hline
\end{tabular}

Figure 2. Distribution channel evolution 


\section{DISCUSSION}

The case study allows us to explore the role of shared ISs to manage distribution channels that are already established, and their contribution to mitigation of the underlying control problems. The case study shows that since the 1980s, CMD managed the established relationship through contract, direct supervision and commission systems. But CMD has found that these systems caused an information asymmetry in the relationship. On one hand, these tools did not allow CMD to gain access to the dealer's private information, about their behaviour, knowledge, performance, and environment. As argued by Martimort (1996), the dealers, due to their proximity, direct treatment and knowledge of the local market, observe aspects of their customers that CMD does not. This is aggravated by the necessity for information about the final market, a critical aspect to CMD. On the other hand, CMD also possesses privileged information, concerning strategies and promotion campaigns for its products, politics of sales, or about the evolution of the sector that would improve the decision-making process of the dealers.

In terms of Merchant and Van der Stede' framework (2003), this bi-directional informational imbalance caused control problems in an inter-organizational context:

Lack of Direction problems, which arise because the contract and the commercial staff fail when transmitting to the dealers exactly what CMD expects from them. The contract is regarded as a mere "starting point" from which the relationship is developed. It is incomplete because it is understood to be the legal framework that outlines the principal obligations and rights of the parties. The commercial department was the only intermediary between CMD and the dealers, which led often to miscommunication, misinterpretation, or oversight. The commercial department staff did not guarantee the control and management of the dealers' activities, given their limited monitoring capacity (Baldenius et al., 2002).

The sole use of the remuneration by commission system is insufficient to motivate and align channel objectives, leading to emergent Motivational problems. CMD offers its dealers its portfolio of customers, through which the dealer can benefit from a fixed level of income from the beginning of the relationship. With this incentive system, a bad dealer in a good area may obtain high commissions 
and vice versa. CMD finds that this system of remuneration failed to motivate either the search for business opportunities or an optimal level of customer service (Mishra et al., 1998). According to Anderson (1985), CMD observed the tendency for some dealers to pay disproportionate attention to customers with a higher sales volume that make the service more profitable. In this sense, another shortfall of the commission system is that it fails to motivate package collection; a fact that meant CMD was unable to reach its targets of container rotation.

Another problem arises from the personal limitations of the dealers. CMD took its first steps towards dealers by recruiting existing transporters who already acted as deliverers of its products. CMD detected lack of training, resources, and capacity within the dealers group. Thus, lacking sale abilities and knowledge, some dealers ignored the different applications of the CMD products. In this sense, the fact that they were good transporting firms did not mean that they were good dealers, according to the very well known Peter Principle. Furthermore, they did not have the information that allowed them to work efficiently.

CMD, motivated by the need to manage these control problems, opted to share information and to supervise the critical aspects of the relationship better. In so doing, they develop an interorganizational IS, in contrast to the literature on marketing that argues that manufacturers should choose to avoid administrative system investments (Anderson and Oliver, 1987). Therefore, the findings show that in an outsourced channel of distribution, the problems defined by Merchant and Van der Stede (2003) persist in an inter-organizational context. Moreover, the incremental delegation of functions causes CMD to be more dependent on (and vulnerable to) the behaviour of the dealers, according to Frazier and Antia (1995), as well as increasing the necessity to manage its distribution channel.

During the period of study, CMD developed a more complex IS to deal with its distribution channel. In contrast to the advice of the consultant firm, CMD opted to control the end-market through the distribution channel. These new ISs help CMD manage the problems of lack of direction by establishing the necessary procedures to carry out activities, by defining the desired results from those aspects that CMD considers critical (new commercialization and administrative functions, container or customer management), when appraising dealers regularly, and when establishing benchmarking systems with the aim of encouraging behaviour that brings desirable results. 
CMD has developed new IS tools that complete the direct supervision carried out by the commercial staff, defining and transmitting acceptable limits of desirable actions. CMD manages the problem of lack of direction and reinforces its direct supervision by supplying its commercial staff with the necessary IS through which they can perform on the basis of solid information, which helps CMD to correct dealers' behaviour. Thus, CMD increases its confidence that dealers will carry out certain desirable actions, or avoid undesirable ones, reducing the risk of a bad service to the final customer.

Additionally, CMD's commercial staff training, assistance, and encouragement to dealers to do the job properly helped to solve the problem of personal limitations. CMD gathers information on its dealers need through ISs, detecting their needs. It also fosters dealer socialization through inter-organizational transference of CMD know-how. The shared character of the ISs provide the dealers with the necessary information to make their decisions on a better-informed basis.

The results of the case study show that when improving the information of the dealers, CMD improves the coordination between both parties, increasing the performance of the distribution channel. Facilitating and increasing the informational flow, CMD tries to mitigate the probability of (and potential damage from) a bad dealer's service. According to Baiman and Sivaramakrishnan (1991), a dealer who has access to the best pre-decision information is able to use it to make better decisions. In this sense, our case study confirms the fact that shared ISs help firms to coordinate and pursue common objectives (Arunachalam, 2004), helping to quickly adopt and adapt to changes in the environment (Chandrashekar and Schary, 1999).

But, as Speklé (2001) argues, we could understand that to share information is not gratuitous. The value of sharing ISs is that improves the performance of the dealers for the attainment of its goals. As Baiman and Sivaramakrishnan (1991) propose, a way in which the manufacturing firms can mitigate any negative effect of improving the dealer's information is to require them to communicate, in turn, their private information. The case shows how a shared IS represents benefits to CMD that are derived from the information that was gathered from the dealers. In addition, the shared IS helps CMD to ensure the reliability of the data, reducing errors, and guaranteeing that it is supervising with correct information. Therefore, 
in CMD's own interest, shared IS makes it possible to check if agreements are being fulfilled, as well as to detect their dealers' weak points, reducing CMD's dependence on its dealers. Furthermore, CMD also uses the information gathered by the IS to benchmark the best dealers, reducing its dealers base. In this sense, integration and coordination via ISs offers the advantages of a hierarchical structure (Gulati and Singh, 1998). The case study shows how the manufacturer not only does not suffer a loss of control, but rather increases the level of control of its dealers and its end-market; without fixed costs and large investment. Thus, manufacturers can see the potential benefits, evaluate the possible risks, and overcome their reluctance to share information with their partners.

In summary, a shared IS improves the management of the CMD partnership. A shared IS completes and re-drives the agreement; in a flexible and non-coercive way, motivating the development of a partnership. With shared IS development, CMD increases information flows, improves congruence of objectives and reduces the number of dealers. CMD accepts the potential risk that dealers may use the information against them, weighing it against the benefits of a consolidated partnership such as shared interests and common targets, or distribution channel dealer compliance.

\section{CONCLUSION}

This case study allows us to explore the role of a shared IS in influencing the ongoing management in an outsourcing context, extending the scope beyond firm limits. We report on how shared ISs are developed in an already established non-equity alliance to increase the extent of outsourcing, and to manage control problems. A shared IS allows the manufacturing firm to continue as the leader in market share and premium prices, which can lead to a sustainable competitive advantage.

An inherent aspect of distribution channels is the conflict of objectives. This causes problems defined in an intra-organizational context (lack of direction, motivational problems, and personal limitations) to persist in an outsourced distribution channel, increasing when the manufacturing firm decides to enhance the quantity and complexity of the tasks delegated to the dealers. This, in 
turn, highlights the need to develop and increase interorganizational ISs that permit sharing information to coordinate and to monitor the key aspects of the relationship.

Case findings show how a manufacturing firm accepts the potential risk that dealers may use the shared information against it weighed against the benefits of developing a partnership. Sharing an IS represents benefits derived from the increased information that, in turn, the manufacturer collects. A shared IS increases the data' reliability, assuring that the manufacturing firm is monitoring operations with proper information. Additionally, a shared IS permits a manufacturer to foresee problems or correct them in a timely manner, as well as offering a way to see the final market through the distribution channel, reducing manufacturer's dependence on its dealers.

Thus, the growth of partnerships demands an IS that could be a key enabler of a strategic relationship. Although ISs have been traditionally seen as tools to improve functions and internal operations, they are necessary to facilitate the administration of management problems that are not eliminated when carrying out activities outside of the firm. In this sense, outsourced distribution channels could also require ISs that allow the manufacturing firm to manage the operations. The case study supplies empirical evidence showing how shared ISs complete and ease the re-drive of inter-firm agreements and constitute a key tool for managing and maintaining inter-firm relationships in a flexible and non-coercive way. Because most distribution channel improvement initiatives would be impossible to implement without timely, effective information sharing among members.

Finally, we must mention some limitations and future research questions. The evidence presented is based on the criterion of a single in-depth study, and therefore it would be interesting to complement these results with data both from dealers' perspective, to analyse their IS's uses, and from other case studies, with the aim of analysing and contrasting possible differences. At the end of our study period, we have found evidence of the coming implementation of a new SAP system. The implications for its use with the dealers would be interesting to analyse. 


\section{REFERENCES}

ANDERSON, E. (1985): "The salesperson as outside dealer or employee: a transaction cost analysis", Marketing Science, 4, 3, 234-254.

ANDERSON, E.; OLIVER, R. (1987): "Perspectives on behavior-based versus outcome-based salesforce control systems", Journal of Marketing, 51, 4, 76-88.

ARUNACHALAM, V. (2004): "Electronic data interchange: an evaluation of alternative organizational forms", Accounting, Organizations and Society, 29, 227-241.

BAIMAN S.; RAJAN, M.V. (2002). "Incentive issues in inter-firm relationships". Accounting, Organizations and Society, 27, 3, 213-38.

BAIMAN, S.; SIVARAMAKRISHNAN, K. (1991): "The value of private predecision information in a principal-dealer context", The Accounting Review, 66, $4,747-766$.

BALDENIUS, T.; MELUMAD, N.; ZIV, A. (2002): "Monitoring in multidealer organizations", Contemporary Accounting Research, 19, 4.

BARUT, M.; FAISST, W.; KANET, J.J. (2002): “Measuring supply chain coupling: an information system perspective". European Journal of Purchasing \& Supply Management, 8, 161-171.

CELLY, K.S.; FRAZIER GL. (1996): "Outcome based and behaviour based coordination efforts in channel relationships", Journal of Marketing Research, $33,2,200-210$.

CHANDRASHEKAR, A.; SCHARY, P.B. (1999): "Toward the virtual supply chain: the convergence of IT and organization", The International Journal of Logistics Management, 10, 2, 27-39.

EISENHARDT, K. (1989): "Agency theory: an assessment and review”, Academy of Management Review, 14, 1, 57-74.

FRAZIER, G.L.; ANTIA, K.D. (1995): "Exchange relationships and interfirm power in channels of distribution", Journal of the Academy of Marketing Science, $23,4,321-326$. 
GULATI, R.; SINGH, H. (1998): "The architecture of cooperation: managing coordination costs and appropriation concerns in strategic alliances", Administrative Science Quarterly, 43, 781-814.

HUANG, Z.; GANGOPADHYAY, A. (2004): "A simulation study of supply chain management to measure the impact of information sharing", Information Resources Management Journal, 17, 3, 20-31.

LAU, H.C.W.; LEE, W.B. (2000): "On a responsive supply chain information system”, International Journal of Physical Distribution \& Logistics Management, 30, 7-8, 598-610.

LI, Z.G.; DANT, R.P. (1997): "An exploratory study of exclusive dealing in channel relationships", Academy of Marketing Science, Journal, 25, 3, 201-213

MARTIMORT, D. (1996): "Exclusive dealing, common agency, and multiprincipals incentive theory", RAND Journal of Economics, 27, 1, 1-31.

MCKNIGHT, H.D.; CHOUDHURY, V.; KACMAR, C. (2002): "Developing and validating trust measures for e-commerce: an integrative typology", Information Systems Research, 13, 3, 334-359.

MERCHANT, K.A. (1985): Control in Business Organizations, Ballinger Publishing Company.

MERCHANT, K.A.; VAN DER STEDE, W.A. (2003): Management Control Systems, Performance Measurement, Evaluation and Incentives, Prentice Hall.

MILES, B.; HUBERMAN, A. (1984): Qualitative Data Analysis: a Sourcebook of New Methods, Beverly Hills: Sage Publications.

MISHRA, D.P.; HEIDE, J.B.; CORT, S.G. (1998): "Information asymmetry and levels of agency relationships", Journal of Marketing Research, XXXV, 277-295.

PAPAZOGLOUS, M.P. (2000): "Business to business electronic commerce issues and solution", Decision Support Systems, 29, 301-304.

PORTER, M.; MILLAR, V. (1985): "How information gives you competitive advantage", Harvard Business Review, 65, 4, 149-160. 
RITTER, T.; GEMÜNDEN, H.G. (2003): “Interorganizational relationships and networks: an overview", Journal of Business Research, 56, 691-697.

ROBEY, D.; ROSS, J.W.; BOUDREAU, M.C. (2002): "Learning to implement enterprise", Information Systems Research, 10, 2, 167-185.

SPEKLÉ, R. (2001): "Explaining management control structure variety: a transaction cost economics perspective", Accounting, Organizations and Society, 26, 419-441.

STERN, L.; EL-ANSARY, A.; COUGHLAN, A. (1996): Marketing Channels. Fifth edition, Prentice Hall.

YIN, R. K. (1984): Case Study Research: design and methods. Sage Publications. 